\title{
IDENTIFICATION OF HUMAN SEX FROM HYOID BONE USING THORACIC COMPUTED TOMOGRAPHY (CT) IMAGES, (A CROSS-SECTIONAL STUDY)
}

\author{
Ola A Sweilum ${ }^{1}$, Rehab M Habib ${ }^{2}$, Mofrih M Hegazy ${ }^{1}$ \\ ${ }^{1}$ Forensic Medicine \& Clinical Toxicology Department, Menoufia University, Egypt. \\ ${ }^{2}$ Radiology Department, Menoufia University, Egypt.
}

Corresponding author: Ola A Sweilum; mobile: 01019898260, e-mail: olaahady@ hotmail.com

Submit Date 2020-08-08

Revise Date 2020-10-17

Accept Date 2020-10-22

Background: The sex determination of the individual plays a vital role in establishing the remains of anthropologists. The characterization of the hyoid bone is made possible by analyzing sexually dimorphic features, enabling it to occasionally be utilized in the sex determination part of establishing the biological profile parameters in skeletal remains. The hyoid bone is the crucial bone in the forensic investigation of neck trauma (as strangulation). This study aims to evaluate the application of the hyoid bone metric measurements and hyoid bone density to identify sex in the Egyptian population using two-dimensional computed tomography (CT) images methodology. Patients and methods: This is a cross-sectional study done on thoracic Computed Tomography (CT) of 103 general Egyptian populations constituting 54 males and 49 females. The statistics against the following parameters were noted from each patient: Bone density in Hounsfield unite by CT (HU), the distance between bilateral greater horns $(\mathrm{GH})$, the distance between bilateral lesser horns (LH), distance from the most anterior end of the hyoid arch to great horns (AP).

Keywords: Hyoid bone, Sex estimation, Bone density, Forensic investigation.

\section{INTRODUCTION}

Demonstrating an unknown human body's identity is considered a pivotal task while undergoing forensic investigation, specifically during the evaluation of severely mutilated cadavers, mass destructions, serious accidents, or encountering skeletal remains. (Balseven-Odabasi A. et al., 2013). The bones remain unimpaired for a long time after death; therefore, bone occasionally serves as a solitary clue for dead body identification (D'Souza, Kiran and Harish, 2013).

Determination of the individual age and sex provides the primary data to identify remains by anthropologists (D'Souza, Kiran and Harish, 2013). Sex determination is an old age problem in identifying human biology in forensic casework as it automatically excludes the possibility of another gender (Mehmet and Maryna, 2013). Various research works had been performed on establishing the sex from the femur, sternum, skull, and pelvic bones. However, these bones might be harmed or deficient, especially in instances of mass destruction, so an alternative method utilizing other bones ought to be created (D'Souza, Kiran and Harish, 2013) (Torimitsu et al., 2018).

The hyoid bone is a solitary bone that carries no bony articulations. It is a small, ' $U$ ' shaped bone suspended from the tips of the stylohyoid ligaments (Priya K S.; Ranzeetha D.; 2015); initially, hyoid is a cartilaginous tissue, and with the time, it gradually turns to bone, serving as an intermediary between postcranial skeleton and skull (Okasi Arash et al., 2018). It is situated in the central part of the neck set between the thyroid cartilage and the root of the tongue. The central part of the bone consists of the body and a pair of the cornea (i.e., the greater and the lesser cornea) (Priya 
K S.; Ranzeetha D.; 2015). Features of sexually dimorphic characterize the hyoid bone, empowering it to occasionally be used in the sex determination aspect of establishing the biological profile in skeletal remains (Urbanova et al., 2013) (Loth, A.; Corny, J.; Santini, L.; et al. (2015).

The hyoid bone is also considered an essential bone in forensic examination of neck trauma (as strangulation or throttling) (Shabana Kumar Naik and Deepak Y. Patil 2005).

The radiographic technique is preferred widely as a quick, economical method for examining the hyoid-larynx area, specifically when dealing with post-mortem examinations (Di Nunno et al., 2004). Also, post-mortem CT (PMCT) using multidetector CT provides promising results and is opted as a routine forensic practice before autopsy and widespread in particular areas (Torimitsu et al., 2015).

Bone-mineral density (BMD) determines the amount of inorganic mineral in bone and is one of the most valuable bone quality analyses in clinical and forensic investigations. Many statistics, such as sexual maturity, genetics, physical activity, lifestyle, dietary calcium, age, affect BMD measurements. It is mandatory to apply certain normative standards for specific age/gender groups (Kranioti, Bonicelli, and García-Donas, 2019). So hyoid bone mineral density is an essential yet neglected parameter, mostly it is related to age, sex, and risk of fracture (Sutlovic et al., 2016).

\section{AIM OF THE WORK}

This study aims to discover the utilization of the hyoid bone metric measurements and hyoid bone density in the identification of sex in the Egyptian population using two-dimensional computed tomography (CT) images.

\section{PATIENTS \& METHODS: \\ Patients:}

This cross-sectional study depends on the perception of the results of thoracic Computed Tomography (CT) on randomly selected 103 Egyptian people (54 males and 49 females) living in the Menoufia governorate.

Patients arrived at Menoufia University hospital and were referred to the radiology department to have a CT scan for other reasons.

The study was affirmed by Menoufia University ethical committee, and individual consent was waived (as it was not considered necessary to be taken from each patient).

\section{Method:}

This study focuses on analyzing the hyoid bone parameters in the Egyptian community using $\mathrm{CT}$ by measuring $\mathrm{GH}, \mathrm{LH}$, and AP (metric measurements). It also depends on measuring the hyoid bone density (HU) to discover their utilization in Egyptians' sex determination.

A Multidetector CT scan was performed using CT equipment (TOSHIBA, ALISON,16 detectors).

Workstation (VITREAI 7) was chosen for imaging information preparing to get multiplanar reproduction pictures and volume-rendered pictures. The hyoid bone was measured in axial images in multiplanar reformate (MIP) with increased thickness to $5 \mathrm{~mm}$. The measurements taken into consideration included the distance between bilateral greater horns $(\mathrm{GH})$ (figure 1), the distance between bilateral lesser horns (LH) (figure 2), distance from the most anterior end of the hyoid arch to GH (AP)(figure 3).

Bone density was measured in Hounsfield unite (HU) by using multiple central parts, including the body and the pair of horns. The mean of these measures was calculated to establish a figure. 


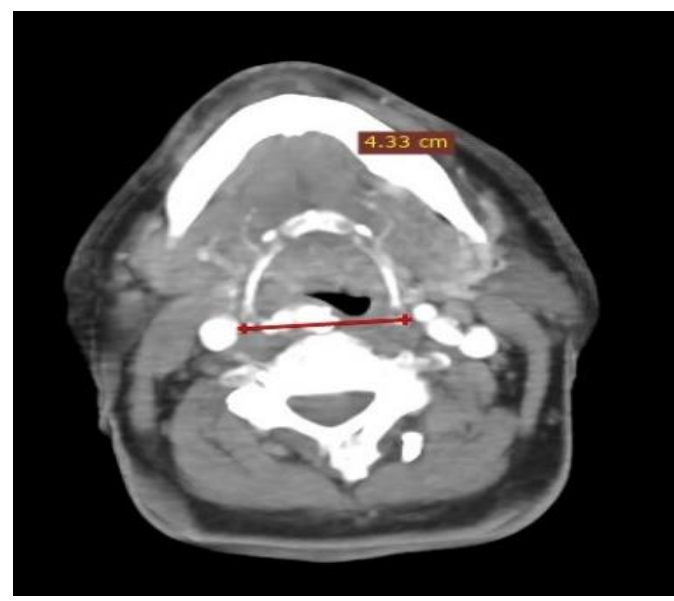

Figure (1): Distance between bilateral greater horns $(\mathrm{GH})$

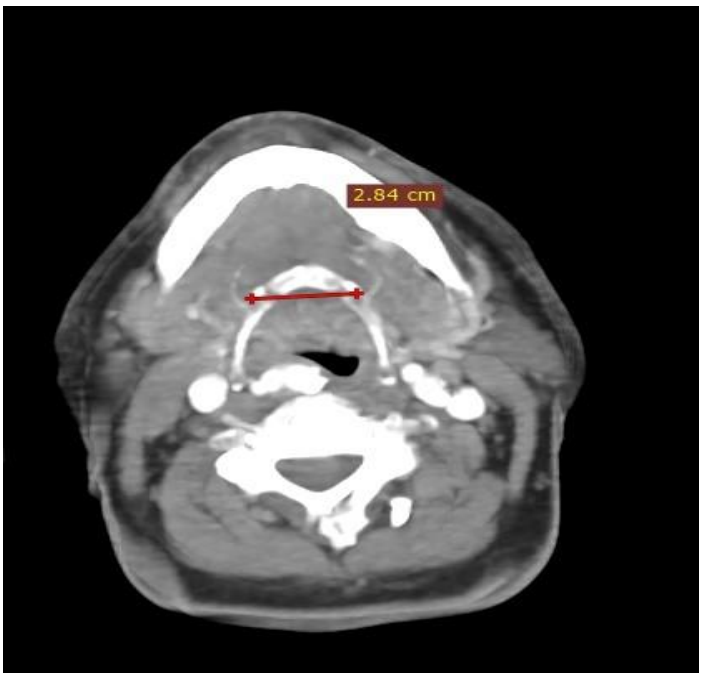

Figure (2): Distance between bilateral lesser horns (LH)

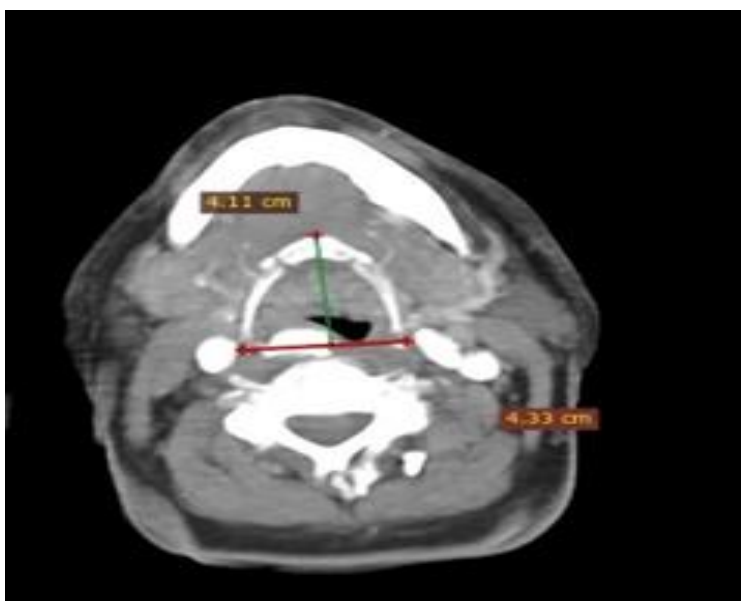

Figure (3): Distance from the most anterior end of the hyoid arch to GH (AP) (green line).

\section{Statistical Analysis:}

Information was taken care of to the PC and investigated utilizing the IBM SPSS programming bundle variant 20.0. (Armonk, NY: IBM Corp). Qualitative data were described in terms of numbers and percentages. The Kolmogorov-Smirnov test was picked to confirm the ordinariness of appropriation. Quantitative information was sorted utilizing standard boundaries, including range (least and most extreme), mean, standard deviation, and median. The Criticalness of the acquired outcomes was decided at the $5 \%$ level.

The student t-test is performed to regularly concentrate on appropriate quantitative factors and build up examination between two contemplated groups.

Receiver operating characteristic curve (ROC): is created by plotting affectability (TP) on Y pivot versus 1-explicitness (FP) on $\mathrm{X}$ hub at the various cut off qualities. The region under the ROC bend portrays the indicative execution of the test. Over half gives an acceptable performance, and the region about $100 \%$ uncovers the best execution for the test. The ROC curve makes it easier to compare the performance of two tests.

Odds ratio (OR): The odd ratio is used to quantify the strength of the correlation occurring among any two groups. In this case, $95 \%$ Confidence Interval of an occasion happening in one hazard group Is contrasted with its chances in the non-hazard group.

Accuracy

Rate of Agreement equal (True positives + True negatives) divided by the Total tested x 100 .

\section{RESULTS}

The present study was a cross-sectional study carried on 103 Egyptian population (54 males (52\%) and 49 females (47.6\%)) arrived at the radiology department at Menoufia university hospital (figure 4). 


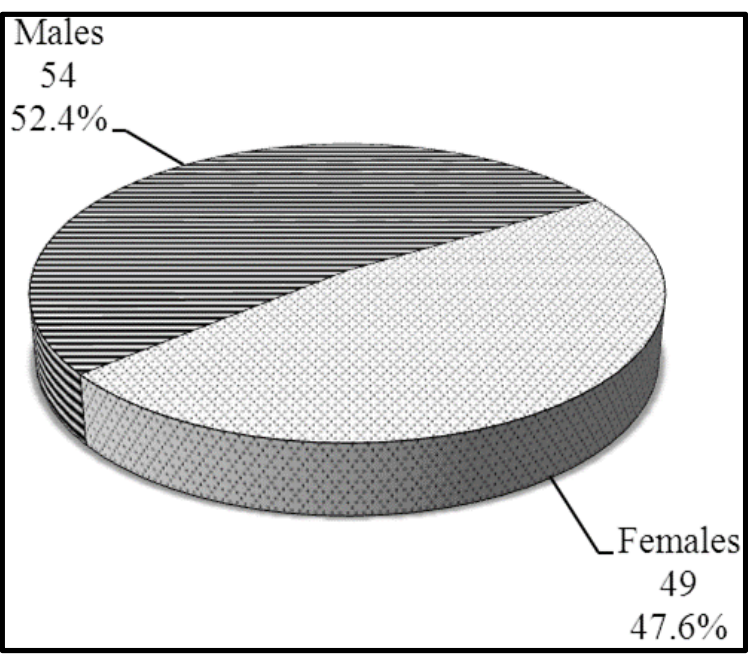

Figure (4): Distribution of the studied cases according to $\operatorname{Sex}(n=103)$

According to their ages, the patients were divided into four groups (child $(\leq 18$ years), young adults (18-35 years), middle (35-55 years), and old ( $>55$ years), with mean $\pm(\mathrm{SD}) 42.4 \pm(20.3)$ years and median 43 (8 $-82)$.

The mean \pm SD was $291 \pm 67.3$, and the median was calculated as 298 in HU. Whereas GH mean \pm SD was $46.1 \pm 7 \mathrm{~mm}$, and its median was $47.9 \mathrm{~m}$. Regarding $\mathrm{LH}$, its mean $\pm \mathrm{SD}$ was $24.2 \pm 1.8 \mathrm{~mm}$, and the median was $24.7 \mathrm{~m}$. The mean $\pm \mathrm{SD}$ of $\mathrm{AP}$ was $34.5 \pm 3.9 \mathrm{~mm}$, and its median was $34.7 \mathrm{~m}$ (table 1).

The differences between male and female patients regarding different hyoid bone measurements were shown in table 2 . Male hyoid bone density (HU) was significantly higher than females $(309.9 \pm 66$ and 270.5 \pm 63.1 , respectively). This difference was statistically significant, with a probability of $\mathrm{P}=0.003$.

Other hyoid bone studied measurements (GH, LH, and AP) showed no significant difference between both sexes as $\mathrm{P}$ values were $0.72,0.26$, and 0.10 , respectively (figure 5).

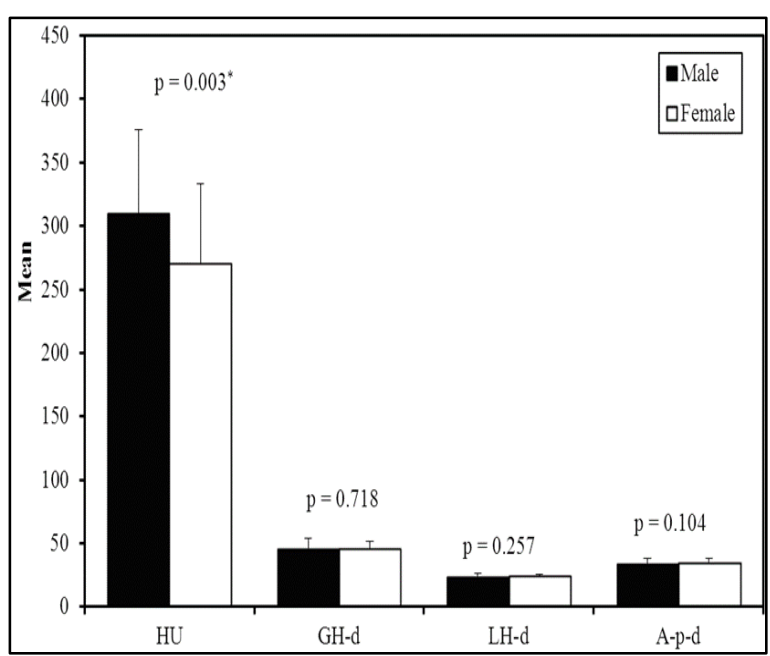

Figure (5): The relation between male and female patients regarding different hyoid bone measurements.

Table 3 shows the hyoid bone measured parameters in males and females in different age groups. HU was higher in males than females in all studied age groups; this difference was statistically significant only in child and young adult age groups ( $\mathrm{P}$ values were 0.008 and $<0.001$ respectively).

$\mathrm{GH}$ showed a non-significant difference between males and females in childhood and old age groups ( $\mathrm{P}$ values were 0.28 and 0.22 respectively), while it was statistically significantly higher in males in young adult and middle age groups $(\mathrm{P}$ values were 0.007 and 0.04 respectively). Moreover, LH showed a non-significant difference between males and females in all age groups ( $\mathrm{P}$ values were $0.35,0.86,0.40$, and 0.54 , respectively).

The AP is significantly higher in a female child compared with male one (with $\mathrm{P}=0.01$ ), while it shows non-significant differences between males and females in all other age groups ( $\mathrm{P}$ values are 0.40, 0.09, 0.94 respectively) (Table 3 ).

Table 4 presents the sensitivity and specificity parameters for different parameters to predict gender.

The accuracy (AUC) of HU (bone density) was 0.70 , which was significantly the most accurate hyoid bone studied 
parameter for sex detection (with $\mathrm{P}=0.001$ ) compared with the accuracy of other metric parameters (GH 0.60, LH 0.51, and AP 0.55).

At a cut-off $>282$, HU's sensitivity was $74.07 \%$, and its specificity was $59.18 \%$. At cut off $>50$, GH's sensitivity was $40.74 \%$, and its specificity was $89.80 \%$. At the cut off $\leq 25.6$, the Sensitivity of LH was $85.19 \%$, and its specificity was $0.0 \%$. Moreover, at the cut-off $\leq 29.2$, AP's sensitivity was 20.37 , and its specificity was 95.92 .

The cut-off values for male sex detection were greater than 282 in $\mathrm{HU}$, greater than 50 in $\mathrm{GH}, \leq 25.6$ in $\mathrm{LH}$, and $\leq 29.2$ in AP.

ROC analysis was used to quantify through the optimum values of different hyoid bone measured parameters. The optimum cut-off value was determined from all sensitivity and specificity values. The sensitivity and specificity of hyoid bone measurements used for sex determination are presented in figure 6.

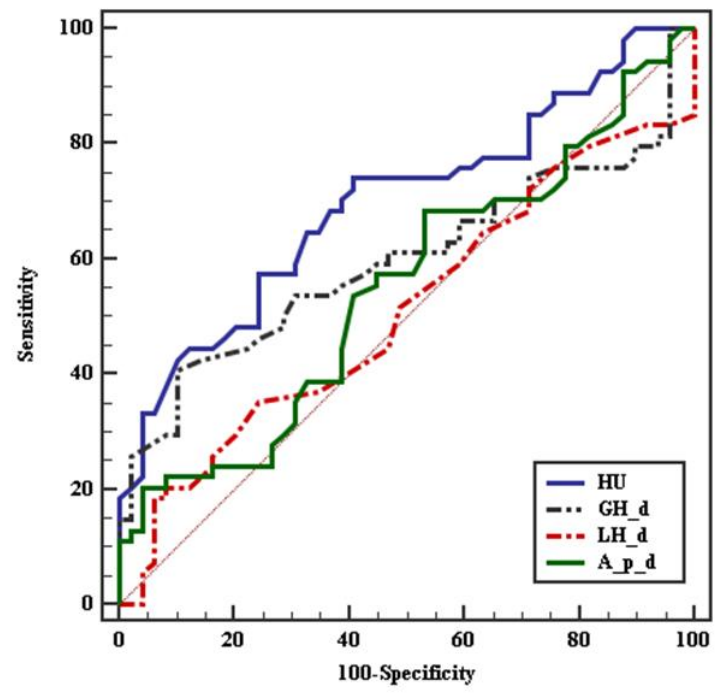

Figure (6): ROC curve for different hyoid bone parameters to predict male vs female

Table (1): Descriptive analysis of the studied cases according to different hyoid bone measured parameters $(n=103)$

\begin{tabular}{|c|c|c|}
\hline & Mean \pm SD. & Median (Min. - Max.) \\
\hline HU & $291.2 \pm 67.3$ & $298(177-379)$ \\
\hline GH & $46.1 \pm 7$ & $47.9(24.2-56.7)$ \\
\hline LH & $24.2 \pm 1.8$ & $24.7(19.3-25.9)$ \\
\hline AP & $34.5 \pm 3.9$ & $34.7(21-41)$ \\
\hline
\end{tabular}

HU: Bone density in Hounsfield unite by CT, GH: Distance between bilateral greater horns, LH: Distance between bilateral lesser horns, AP: Distance from most anterior end of hyoid arch to the great horns.

Table (2): Relation between sex and different hyoid bone measured parameters $(n=103)$

\begin{tabular}{|c|c|c|c|c|}
\hline & \multicolumn{2}{|c|}{ Sex } & \multirow{2}{*}{$\mathbf{t}$} & \multirow[b]{2}{*}{$\mathbf{p}$} \\
\hline & Male $(n=54)$ & Female $(n=49)$ & & \\
\hline \multicolumn{5}{|l|}{ HU } \\
\hline Mean \pm SD & $309.9 \pm 66$ & $270.5 \pm 63.1$ & \multirow{2}{*}{$3.09^{*}$} & \multirow{2}{*}{$0.003^{*}$} \\
\hline Median (Min. - Max.) & $324(180-379)$ & $270(177-369)$ & & \\
\hline \multicolumn{5}{|l|}{ GH } \\
\hline Mean \pm SD. & $45.9 \pm 8.4$ & $46.4 \pm 5.1$ & \multirow{2}{*}{0.36} & \multirow{2}{*}{0.718} \\
\hline Median (Min. - Max.) & $49.2(26.3-56.7)$ & $47.2(24.2-52)$ & & \\
\hline \multicolumn{5}{|l|}{ LH } \\
\hline Mean \pm SD. & $24 \pm 2$ & $24.4 \pm 1.5$ & \multirow{2}{*}{1.14} & \multirow{2}{*}{0.257} \\
\hline Median (Min. - Max.) & $24.7(19.4-25.9)$ & $24.8(19.3-25.6)$ & & \\
\hline \multicolumn{5}{|l|}{$\mathbf{A P}$} \\
\hline Mean \pm SD. & $33.9 \pm 4.5$ & $35.1 \pm 2.9$ & \multirow{2}{*}{1.64} & \multirow{2}{*}{0.104} \\
\hline Median (Min. - Max.) & $34.6(21-40)$ & $35.4(27.9-41)$ & & \\
\hline
\end{tabular}

t: Student t-test p: p value for comparing between the studied groups

*: Statistically significant at $\mathbf{p} \leq \mathbf{0 . 0 5}$ 
Table (3): Relation between different hyoid bone parameters regarding age and sex $(n=103)$

\begin{tabular}{|c|c|c|c|c|}
\hline & \multicolumn{4}{|c|}{ Age (years) } \\
\hline & $\begin{array}{c}\text { Child }(\leq 18) \\
(n=16)\end{array}$ & $\begin{array}{c}\text { Young adult }(>18-35) \\
(n=25)\end{array}$ & $\begin{array}{c}\text { Middle age }(>35-55) \\
(n=34)\end{array}$ & $\begin{array}{c}\text { Old }(>55) \\
(n=28)\end{array}$ \\
\hline \multicolumn{5}{|c|}{$x_{2}(m-\infty)$} \\
\hline Males & $292.9 \pm 40.2$ & $364.9 \pm 4.41$ & $342.0 \pm 43.6$ & $221.67 \pm 50.37$ \\
\hline Females & $231.6 \pm 26.3$ & $311.57 \pm 37.96$ & $315.9 \pm 45.7$ & $206.9 \pm 34.51$ \\
\hline p & $\mathbf{0 . 0 0 8}^{*}$ & $<0.001^{*}$ & 0.120 & 0.366 \\
\hline \multicolumn{5}{|l|}{ GH } \\
\hline Males & $31.56 \pm 6.79$ & $50.75 \pm 2.58$ & $50.86 \pm 3.01$ & $46.20 \pm 2.50$ \\
\hline Females & $39.0 \pm 13.05$ & $47.91 \pm 2.23$ & $48.77 \pm 2.20$ & $45.21 \pm 1.72$ \\
\hline p & 0.283 & $0.007^{*}$ & $0.035 *$ & 0.224 \\
\hline \multicolumn{5}{|l|}{ LH } \\
\hline Males & $20.44 \pm 1.29$ & $24.55 \pm 0.67$ & $25.18 \pm 0.54$ & $24.83 \pm 0.46$ \\
\hline Females & $21.7 \pm 2.63$ & $24.46 \pm 1.41$ & $24.64 \pm 0.43$ & $24.94 \pm 0.54$ \\
\hline $\mathbf{p}$ & 0.349 & 0.862 & 0.400 & 0.544 \\
\hline \multicolumn{5}{|l|}{ AP } \\
\hline Males & $26.44 \pm 3.17$ & $36.12 \pm 3.27$ & $36.14 \pm 1.70$ & $34.88 \pm 1.69$ \\
\hline Females & $29.62 \pm 1.21$ & $35.14 \pm 2.47$ & $37.29 \pm 2.08$ & $34.84 \pm 1.63$ \\
\hline p & $0.012^{*}$ & 0.401 & 0.085 & 0.943 \\
\hline
\end{tabular}

*: Statistically significant at $\mathbf{p} \leq \mathbf{0 . 0 5}$

Table (4): Agreement (sensitivity, specificity) for different measured parameters to predict male vs female.

\begin{tabular}{|l|c|c|c|c|c|c|c|c|}
\hline & AUC & P & 95\% C.I & Cut off & Sensitivity & Specificity & PPV & NPV \\
\hline HU & 0.70 & $0.001^{*}$ & $0.60-0.80$ & $\mathbf{> 2 8 2}$ & 74.07 & 59.18 & 66.7 & 67.4 \\
\hline GH-d & 0.60 & 0.090 & $0.49-0.71$ & $\mathbf{> 5 0}$ & 40.74 & 89.80 & 81.5 & 57.9 \\
\hline LH-d & 0.51 & 0.869 & $0.40-0.62$ & $\mathbf{5 2 5 . 6}$ & 85.19 & 0.00 & 48.4 & 0.0 \\
\hline A-p-d & 0.55 & 0.376 & $0.44-0.66$ & $\mathbf{2 9 . 2}$ & 20.37 & 95.92 & 84.6 & 52.2 \\
\hline
\end{tabular}

AUC: Area Under a Curve

NPV: Negative predictive value

\section{DISCUSSION}

The current study was based on the observations of 103 (54 male and 49 Female) patients who arrived at the faculty of medicine, Menoufia University, Egypt.

Moreover, measuring the hyoid bone density and three of its metric measurements (GH, LH, AP) using computed tomography scans to identify the sex of the Egyptian population sample.

Using CT for hyoid bone measurements is preferred as it is a non-invasive method. Moreover, sex identification of partially skeletonized or a putrefied cadaver appears to be time-consuming, and usually, the joints of hyoid bone are often damaged by the process of taphonomy, making it difficult to take accurate measurements.

Male hyoid bone density (HU) in the current study was significantly higher than the female one. This observed difference may have been caused by more bone size in males than females; also, females experience significant hormonal variability due to which bone health gradually declines.

The same was reported by Ellie Fisher (Fisher et al., 2016) as they found that lower 
female hyoid bone density compared with male one.

It was observed in the present study that no statistically significant differences between males and females regarding measured metric hyoid bone parameters $(\mathrm{GH}$, LH, and AP). Similar results were found in the study of Pollard J. et al. (Pollard J et al., 2011), who observed 76 hyoid bones (38 men and 38 women).

Siamak Soltani et al. (Siamak S. et al., 2017) also discovered a nearly equivalent male and female hyoid bone width and length. Balseven-Odabasi et al. determined close hyoid bone measurements in both sexes (Balseven-Odabasi A. et al., 2013).

Unlike Fakhry N. et al. (Fakhry N. et al., 2015) and Harjeet et al. (Harjeet et al., 2010), who reported a greater male value hyoids metric dimensions compared with female ones. Researchers such as Urbanová et al. ( Urbanová $P$ et al., 2013) proved that male hyoids are generally larger than female ones.

In the present study, Greater horn $(\mathrm{GH})$ shows a non-significant difference between both sexes. However, Deepak Herald D "Souza et al. (D'Souza, Kiran and Harish, 2013) suggested that the length, width of the greater horn of the hyoid bone were more in the male gender.

In a study done on the Bengali population by MukhopadhyayPP. (Mukhopadhyay PP, 2012), All the parameters included in this study were greater in males than females (the distance between the lesser cornua, width, length of the greater cornua).

Priya and Savitha V studies found that the transverse distance between the greater cornua in males was higher than females (Santhi Priya and Aruna Kumari, 2016) (Savitha V. et al., 2019).

In the present study, it is observed that AP showed a non-significant difference between both sexes. The same was observed by Savitha V. et al. (Savitha V. et al., 2019).

In the current study, HU was higher in males than females in all age groups; this difference was statistically significant in child and young age groups $(\mathrm{P}$ values were 0.008 and $<0.001$ respectively). $\mathrm{GH}$ was higher in males in young adult, middle age, and old age groups. In contrast, AP is significantly higher in females only in the child age group. LH was nearly the same in all age groups.

In contrast, Ellie Fisher et al. (Fisher et al., 2016) found no significant difference between both sexes regarding hyoid bone density in pediatrics. While in adults, they observed that bone density was significantly lower, especially in old adult females.

Ramagalla (Ramagalla et al., 2014) In another study, found that $\mathrm{GH}$ increases with increasing age in males, but in females, there is a variation of size only up to 25 years of age.

Among the various hyoid bone measured parameters in the present study, the bone density was the best indicator for sex identification. This is unlike the conclusion of Okasi Arashi (Okasi A.; et al., 2018), who suggested that the length of the greater horn is the best indicator for sex identification.

\section{CONCLUSION}

The current study uncovered the effectiveness of using CT pictures to evaluate the sexual dimorphism of the hyoid bone. HU was the unique hyoid indicator that can assist accurate sex classification or sexually dimorphic in the Egyptian population. So, it can be helpful for forensic investigators for sex identification.

\section{RECOMMENDATIONS}

$1-\mathrm{We}$ need to increase the number of radiological studies for sex determination, as we can add other bones to facilitate forensic anthropologic evaluation. 
2- As there are ethnic differences within the national population, we recommend further hyoid bone studies in other governorates in Egypt.

\section{Conflicts of interest:}

The authors declare that they have no conflicts of interest in this research.

\section{REFERENCES}

Balseven-Odabasi, A.; Yalcinozan, E.; Keten, A.; Akcan, R.; Tumer, A. R.; Onan, A.; Canturk, N.; Odabasi, O. and Hakan Dinc, A. (2013): Age and sex estimation by metric measurements and fusion of hyoid bone in a Turkish population', J Forensic Leg Med, 20(5), pp. 496-501.

Di Nunno, N.; Lombardo, S.; Costantinides, F. and Di Nunno, $C$. (2004): Anomalies and alterations of the hyoid-larynx complex in forensic radiographic studies. Am J Forensic Med Pathol, 25(1), pp. 14-9.

D'Souza, D. H.; Kiran, J. and Harish, S. S. (2013): Determination of Sex by Shape and Size of Hyoid Bone. J Indian Acad Forensic Med., 35(2), pp. 145-147.

Fisher, E.; Austin, D.; Werner, H. M.; Chuang, Y. J.; Bersu, E. and Vorperian, H. K. (2016): Hyoid bone fusion and bone density across the lifespan: prediction of age and sex. Forensic Sci Med Pathol, 12(2), pp. 14657.

Harjeet K.; Synghal S.; Kaur G.; Aggarwal A.; Wahee P. (2010): Time of Fusion of Greater Cornu with Body of Hyoid Bone in Northwest Indians. Legal medicine (Tokyo, Japan), 12(5).

Kranioti, E. F.; Bonicelli, A. and GarcíaDonas, J. G. (2019): Bone-mineral density: clinical significance, methods of quantification, and forensic applications. Research and Reports in Forensic Medical Science: 9, pp. 9-21.
Loth, A.; Corny, J. ; Santini, L. ; et al. (2015): Analysis of Hyoid-Larynx Complex Using 3D Geometric Morphometrics. Dysphagia. 30(3):357364. doi:10.1007/s00455-015-9609-2.

Mehmet, Y. I. \& Maryna, S. (2013): Textbook of The Human Skeleton in Forensic Medicine, 3rd edition. Charles C. Thomas Publisher; 3rd ed. edition (24 Sept. 2013), p. 143.

Mukhopadhyay PP. (2012): Determination of Sex from an Autopsy Sample of Adult Hyoid Bones. Medicine, science, and the law, 52(3).

Okasi Arash, S. M. H.; Behnoush, B; Shakori Rad A. (2018): Sex Identification by Morphometric Study of Hyoid Bone. International journal of medical toxicology and forensic medicine, 8, pp. 145-150.

Pollard, J.; Piercecchi-Marti, MD; Thollon, L.; Bartoli, C.; Adalian, P.; Bécart-Robert, A.; et al., (2011): Mechanisms of Hyoid Bone Fracture After Modelling: Evaluation of Anthropological Criteria Defining Two Relevant Models. Forensic science international, 212(1-3).

Priya K S.; Ranzeetha D.; (2015): Determination of Sex from Morphometry of Hyoid Bone. Indian J Clin Anat Physiol:2(3):157-161.

Ramagalla, D.; Sadanandam, D. and Rajashree, D. T. (2014): Morphometry of human hyoid bone for sex determination. IOSR Journal of Dental and Medical Sciences, 13, pp. 96-99.

Santhi P. and Aruna Kumari, G. (2016): Sexual Dimorphism with The Shape Of Hyoid Bone. IP Indian journal of anatomy and surgery of head, neck and brain, 2(1), pp. 16-20.

Sarah C. Kindschuh; Tosha L. Dupras; Libby W. Cowgill. (2010): Determination of Sex from the Hyoid 
Bone. American journal of physical anthropology, 143(2).

Savitha V.; Sunitha R.; Sharada BM. (2019): Morphometric Determination of Sex of Hyoid Bone. National Journal of Clinical Anatomy, 8 (3), pp. 112-116.

Shrabana Kumar Naik, Deepak Y. Patil (2005): Fracture of hyoid bone in cases of asphyxial deaths resulting from constricting force round the neck'.Journal of Indian Academy of Forensic Medicine: 32(1).

Soltani, S.; Aghakhani,K.; Fallah,F. (2017): Sex Prediction Potential of Hyoid Metric Measurements in Iranian Adults. Legal medicine (Tokyo, Japan), 25.

Sutlovic, D., Boric, I., Sliskovic, L., Popovic, M., Knezovic, Z., Nikolic, I., et al., (2016): Bone mineral density of skeletal remains: Discordant results between chemical analysis and DXA method. Leg Med (Tokyo):20, pp. 18-22.

Torimitsu, S., Makino, Y., Saitoh, H., Ishii, N., Yajima, D., Inokuchi, G., et al., (2018): Determination of sex on the basis of hyoid bone measurements in a Japanese population using multidetector computed tomography. Int J Legal Med, 132(3), pp. 907-914.

Torimitsu, S., Makino, Y., Saitoh, H., Sakuma, A., Ishii, N., Hayakawa, et al., (2015): Stature estimation in Japanese cadavers based on pelvic measurements in three-dimensional multidetector computed tomographic images. Int J Legal Med, 129(3), pp. 633-9.

Urbanova, P., Hejna, P., Zatopkova, L. and Safr, M. (2013): What is the appropriate approach in sex determination of hyoid bones? J Forensic Leg Med, 20(8), pp. 996-1003. 
تحديد الجنس البشري من العظم اللامي باستخدام باستخدام صور الاشعه المقطعيه علي الصدر (CT)

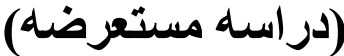

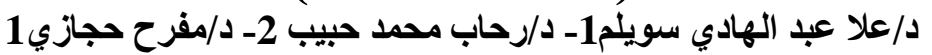

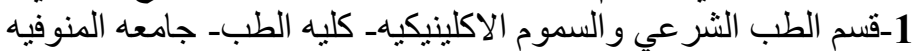

2- قسم الاشعه التشخيصيه- كليه الطب- جامعه المنوفيه

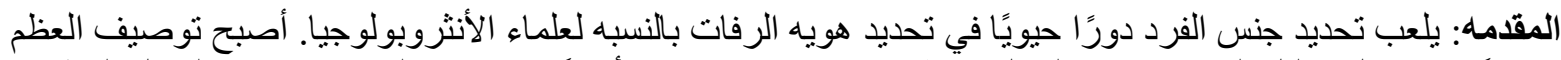

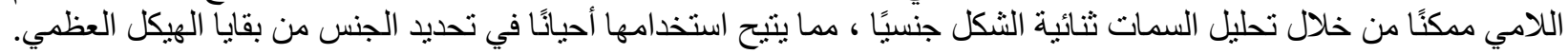

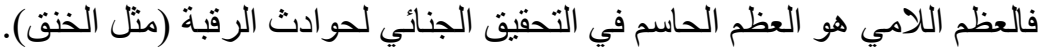
تهدف هذه الدر اسة إلى تقييم تطبيق القياسات المنرية للعظم اللامي و كثافة العظم اللامي لتحديد الجنس في السكان المصريين

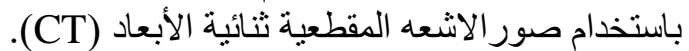
المواد والطرق: هذه در اسة مقطعية أجريت باستخدام الاشعه المقادية المقعيه علي للصدر (CT) لـ 103 من السكان المصريين 54منهم ذكور و 49 منهم إناث.

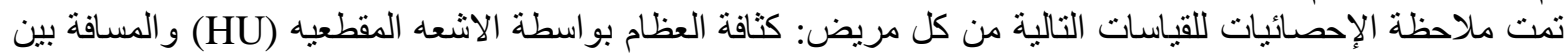

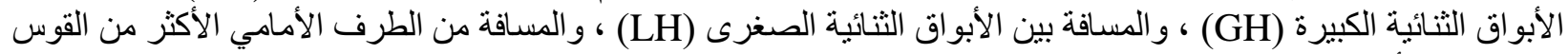

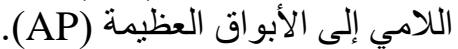

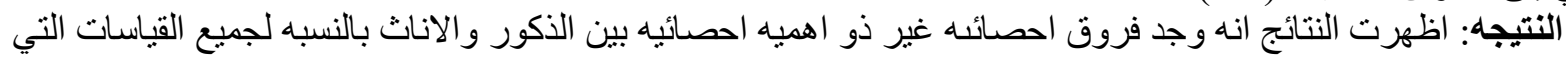

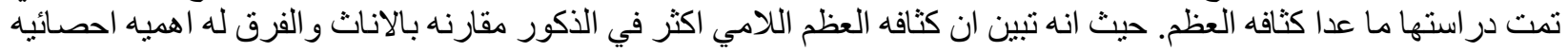

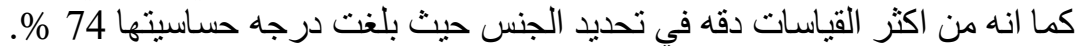
الاستتناج: يمكن استخدام قياسات العظم اللامي في تحديد الجنس بدقه عن طريق الاشعحه المقطعيه ويعتبر قياس كثافه العظم

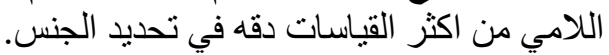

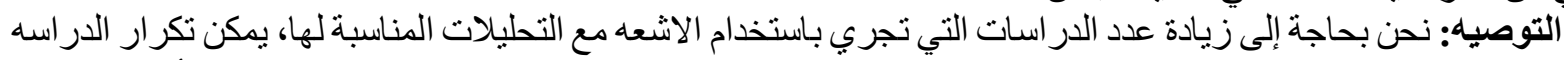

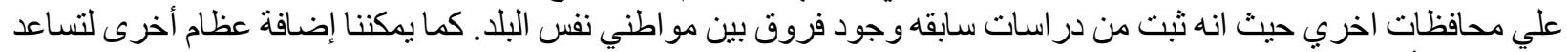
في التقييم الأنثروبولوجي الثراتي. 